\title{
A IMPORTÂNCIA DA FAMÍLIA NA EDUCAÇÃO INFANTIL
}

\author{
Antônia Avanildes Cardozo ${ }^{1}$ \\ Adriana Aparecida da Cruz Alves ${ }^{2}$ \\ Elizângela Leite da Silva Macedo ${ }^{3}$ \\ Gleice Aparecida Martins ${ }^{4}$ \\ Sara Lima Nascimento ${ }^{5}$ \\ Silvia Casmal de Freitas ${ }^{6}$ \\ Taynara Rodrigues Queiroz ${ }^{7}$
}

RESUMO: Este artigo tem como objetivo discutir a importância da família na educação infantil e o papel dos pais na escola. Entende-se que a família deve se engajar com a escola para favorecer o aprendizado e a educação de seus filhos. O objetivo deste artigo foi levantar, por meio de pesquisa bibliográfica, a importância da relação entre a família e a instituição de ensino e seus efeitos na aprendizagem da criança. Concluiu-se que família e escola juntas são de fundamental importância na promoção da aprendizagem da criança, visto que é necessário que a família conheça os objetivos da proposta escolar de acompanhar o desenvolvimento das práticas educativas infantis e se engajar na conquista do sucesso. na aprendizagem e formação do indivíduo.

Palavras chave: Aprendizagem. Educação Infantil. Família.

ABSTRACT: This article aims to discuss the importance of the family in early childhood education and the role of parents in school. It is understood that the family must engage with the school to favor the learning and education of their children. The aim of this article was to raise, through bibliographical research, the importance of the relationship between the family and the educational institution and its effects on the child's learning. It was concluded that family and school together are of fundamental importance in promoting children's learning, as it is necessary for the family to know the objectives of the school

\footnotetext{
I Graduada em Pedagogia pela Universidade Federal do Rio Grande do Sul - UFRG, Especialista em Educação Ambiental pelas Faculdades Integradas Mato-Grossenses de Ciências Sociais e Humanas - ICE.

${ }^{2}$ Graduada em Pedagogia pela Universidade de Cuiabá - UNIC. Especialista em Educação Infantil e Alfabetização pela Faculdade Poliensino - FP.

3 Graduada em Pedagogia Faculdade Varzeagrandense de Ciências Humanas, Especialista em Educação Infantil e Especial pela Faculdade das Águas Emendadas - FAE.

${ }^{4}$ Graduada em Pedagogia pela Universidade de Cuiabá - UNIC. Especialista em Psicopedagogia Institucional pela Faculdade São Luíz.

5 Graduada em Pedagogia pela Faculdade INVEST de Ciências e Tecnologia, Graduada em Letras / Literatura pela Universidade Federal de Mato Grosso, Especialista em Educação de Jovens e Adultos - EJA pela Faculdade Integrada de Várzea Grande - FIAVEC, Especialista em Alfabetização e Letramento pela Faculdade Metropolitana.

${ }^{6}$ Graduada em Pedagogia pela Universidade de Cuiabá - UNIC. Especialista em Educação Infantil com Ênfase em Alfabetização pela Faculdade INVEST de Ciências e Tecnologia.

${ }_{7}$ Graduada em Pedagogia pelo Centro Universitário de Varzea Grande - UNIVAG.
} 

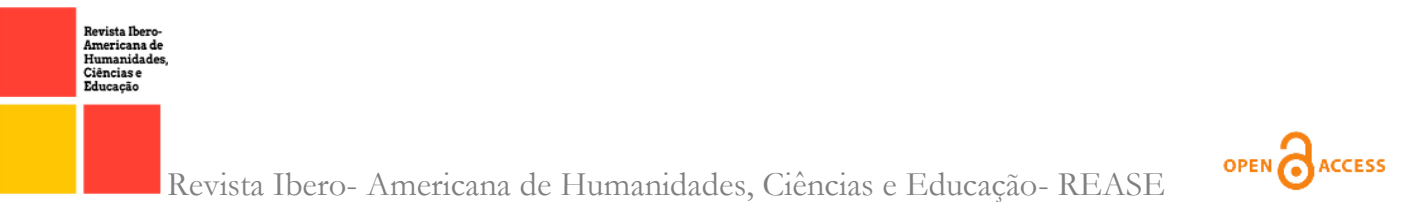

proposal to monitor the development of children's educational practices and engage in achieving success. in the learning and training of the individual.

Keywords: Learning. Early Childhood Education. Family.

\section{INTRODUÇÃO}

Tendo em vista que a relação entre a família e a escola pode colaborar ou interferir na formação, no desenvolvimento e na construção do conhecimento da criança durante a educação infantil, pode-se afirmar que ambas as instituições desempenham um importante papel complementar no processo de aprendizagem da criança. A escola é o local onde se dá a interação entre professores e alunos e dá acesso ao conhecimento formal sobre um determinado contexto cultural e é uma ferramenta necessária ao processo educativo. Sabese, entretanto, que a aprendizagem não ocorre apenas no ambiente escolar e que a criança possui outras conexões que não devem ser esquecidas ou subestimadas nesse processo.

A interagir com a família, a criança estabelece e constrói conhecimentos em um espaço de convivência onde aprende e incorpora valores éticos e significados afetivos. As instituições de educação infantil precisam interagir com os pais para compreender esses valores e significados e combiná-los com o trabalho realizado, com os materiais pedagógicos e espaços disponíveis adaptados para a criança em sua fase inicial de escolarização, quando se inicia a modelagem de seu comportamento e confiança (UNESCO, 2003). A escola deve fornecer os meios para a construção do conhecimento e a promoção do desenvolvimento dos alunos, principalmente na primeira fase da educação infantil, que visa o desenvolvimento integral da criança. A família e a escola devem sempre buscar um ambiente saudável para a criança e promover sua educação e aprendizagem, pois a qualidade da educação infantil depende cada vez mais da colaboração entre a família e a escola.

A escola deveria ser uma instituição especializada na educação com a finalidade de estar à disposição da família e da criança, possibilitando atividades e programas culturais e pedagógicos. Para Piletti (2004) nem sempre é assim, uma vez que as experiências sociais não estão necessariamente incluídas no currículo escolar, uma vez que o foco se limita em parte aos problemas de desenvolvimento da criança, sem vê-la como um ser contextualizado histórica, social e culturalmente. 


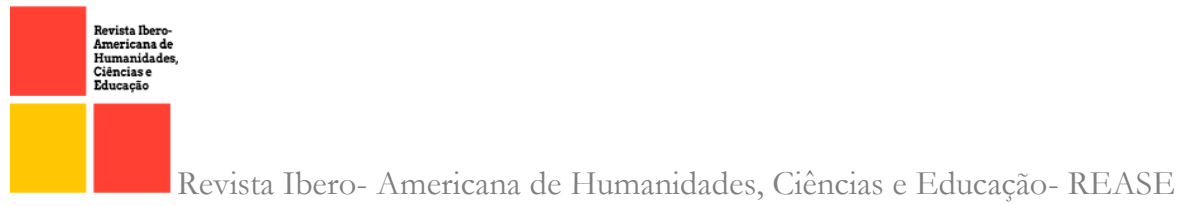

Para Souza (2009) o bom relacionamento entre família e escola deve estar presente em todo trabalho educativo, pois é uma ação comum, orientando e discutindo diferentes questões para definir os meios de ação que podem proporcionar o bom desenvolvimento e desempenho social e escolar da criança. Neste contexto, foram definidas as seguintes hipóteses de trabalho: a aprendizagem da criança está ligada à forma como a família se relaciona com o sujeito e com a instituição escolar; Algumas famílias entendem que a responsabilidade pela educação dos filhos é exclusivamente escolar, visto que não participam ativamente da escola e da vida social dos filhos; os aspectos afetivos na relação família / escola podem favorecer a fase inicial de aclimatação da criança; e a escola deve promover atividades que envolvam a família na participação na vida escolar dos filhos e estimule a participação no processo educacional da criança.

\section{DESENVOLVIMENTO}

\section{I A importância da família na educação infantil}

Segundo Oliveira (20II) espera-se que a família crie seus filhos para se comportar de acordo com padrões predefinidos e desenvolver um comportamento socialmente esperado. As ações e expectativas dos pais em relação ao filho e os modelos de comportamento que oferecem, ao mesmo tempo que permitem a percepção do que valorizam, também estimulam o indivíduo a se adaptar para se adaptar à vida social. A participação dos pais em conselhos de escola ou na organização de eventos escolares ajuda a criança a motivar-se, a ganhar experiência e a aproximar-se deste contexto. Assim, a família assume o papel de apoio à criança e é reconhecido que a ausência dos pais pode levar a problemas de leitura e aprendizagem.

Para Winnicott (2005) apud Araújo (2010) o principal papel da mãe é criar e cuidar do filho, criar um ambiente confortável para o desenvolvimento saudável da criança, proporcionar desempenho adequado em relação às tarefas, ter maior probabilidade de adaptação e também de personalidade. desenvolver para atender às demandas de suas necessidades mais importantes.Ainda no que se refere ao papel da família, segundo Referencial Curricular Nacional, constata-se que ela não está sozinha: 
No geral, as famílias que porventura tiverem dificuldades em cumprir qualquer uma de suas funções para com a criança deverão receber toda ajuda possível das instituições de educação infantil, da comunidade, do poder público, das instituições de apoio para que melhorem os desempenhos junto às crianças (BRASIL, 1998, p. $84)$.

Esse papel de apoio à família que a escola desempenha, entre outras instituições, é relativamente recente na história, assim como a forma como os pais se relacionam com os filhos. Nos tempos modernos, quando começaram a surgir as primeiras instituições de ensino, os pais passaram, em relação ao passado, a se preocupar mais com os filhos e a tentar tê-los por perto para cuidar de sua educação. $\mathrm{O}$ ambiente sentimental passou a ser diferente e os pais começaram a se aproximar dos filhos e buscar uma vida familiar. A família precisou aprender a ouvir, prestar atenção e agir com paciência e cuidado para que a criança construa um vínculo afetivo entre eles, para que vejam os pais como exemplo e, diante dos obstáculos, busquem sua segurança (ARIÉS, 2006).

Segundo Ariés (2006) Com o fim da Idade Média, os filhos começam a ganhar lugar de destaque no contexto familiar. No século XVII a família tinha um papel diferente e a sua principal característica que a distingue das famílias medievais é que os filhos se tornam elementos indispensáveis na vida dos pais e a partir desse momento a família passa a preocupar-se com a carreira, a educação e o futuro. seus filhos.

Portanto, fica evidente que tanto a mudança no padrão de relacionamento entre a família e a criança quanto o surgimento das instituições escolares caminham lado a lado, embora não necessariamente de forma coerente. Essa situação ressalta a importância agora atribuída à infância. Se a criança era anteriormente tratada como um jovem adulto e não buscava uma compreensão efetiva de suas reais necessidades, agora requer atenção especial tanto das famílias quanto das instituições escolares, criando novos papéis para ambas. Nesse contexto, parte-se do pressuposto de que, se inicialmente as instituições familiares e escolares só existiam lado a lado, à medida que essas instituições amadurecem e mudam, elas passam a se conectar e se complementar (ARIÉS, 2006).

Para Piletti (2004) o envolvimento da família é essencial para uma educação escolar de sucesso. Isso pode ser alcançado por meio dos serviços que a escola presta à comunidade e com ela, envolvendo-a em uma associação que, além de fornecer informações à sociedade, é 
uma predisposição positiva para atender às necessidades da escola. São apresentadas sugestões relevantes para o reagrupamento familiar para que as crianças também possam conhecer os pais, brinquedos e locais de residência dos seus companheiros e, assim, conhecer a realidade e integrar as famílias.

A família é fundamental na vida dos filhos, de acordo com Froebel (200I apud Araújo (2010), atualmente, o processo de educação dos filhos encontra dificuldades relacionadas à disponibilidade de tempo para os pais acompanharem as solicitações dos filhos. A família, muitas vezes em busca de sobrevivência, vê os pais submetidos a dias cansativos de trabalho, que reduzem o contato com os filhos e dificultam o acompanhamento $e$ a satisfação das expectativas escolares e da participação dos filhos na vida escolar.

Segundo Marchesi (2004) apud Souza (2009) a educação não é uma tarefa que só pode ser delegada à escola. A cooperação e a colaboração familiar são necessárias, os pais precisam contribuir para o alcance dos objetivos e ideais educacionais para superar as dificuldades encontradas no dia-a-dia dos profissionais nas instituições.

Para Souza (2009) a família mudou como um sistema de vínculos afetivos em que o ambiente familiar pode contribuir positivamente para o desempenho da criança. Os pais são o apoio que toda criança precisa, e acontece que sem um lar estruturado as dificuldades enfrentadas pelos alunos serão acentuadas, afetarão a escola e a criança poderá ter mais problemas de leitura e aprendizagem.

De acordo com Araújo (2010) a família deve valorizar e nutrir seus filhos, pois os pais, em seus aspectos psicológicos, físicos, intelectuais e sociais, são os maiores responsáveis pelo desenvolvimento, aprendizagem e educação de seus filhos.

A família deve exercer esse papel fundamental, pois é importante acompanhar o desenvolvimento escolar dos filhos. A escola sozinha não pode ter sucesso, dependendo da presença dos pais na formação da criança. A família tem a função psicossocial de promover e adaptar seus filhos a uma cultura de responsabilidade vinculada à criança. Os pais devem oferecer proteção e cuidado, garantindo condições dignas aos filhos, contribuindo para uma socialização baseada nos valores desenvolvidos na estrutura familiar. O papel da família é 
também fornecer suporte emocional à criança, possibilitando-lhe estabelecer vínculos satisfatórios e garantir sua integridade física e mental (SALVADOR et al., 1999).

$\mathrm{Na}$ relação com a família, a criança aprende a encontrar estratégias para alcançar os resultados desejados diante dos desafios e a reconhecer seus direitos e deveres nas situações de aprendizagem na educação. Para Salvador et al. (1999) os pais devem oferecer proteção básica, garantindo a autonomia de seus filhos e criando uma vida saudável com valores positivos que possam controlar o comportamento da criança para que ela aprenda a atender suas necessidades emocionais e sociais, estimulando seu papel educativo.

Segundo Sánchez, Martinez e Peñalver (2003) a família é o primeiro núcleo de ação para a criança, modelando sua construção a partir das relações que se estabelecem de acordo com suas necessidades por meio de um processo de expectativas e desejos que se manifestam em cada família e determinam o comportamento dos filhos. Os pais estabelecem um vínculo com o filho, permitindo atenção e cuidado em todos os momentos significativos da construção de sua identidade. Nesse processo de construção, a criança precisa ser vista e reconhecida em sua individualidade na escola, construindo sua autonomia e independência, deixando de ser um apego à família para encontrar seu próprio espaço.

De acordo com Moreno e Cubero (1990) apud Salvador et al., (1999) as experiências em que as famílias propõem estratégias educativas aos filhos colocam em prática determinadas relações, estabelecendo normas julgadas eficazes para a educação. Essas estratégias exercitam nas crianças o desenvolvimento do autocontrole e do comportamento adequado na educação, no presente e no futuro.

Em muitos casos, a conquista da autonomia da criança é planejada pelos pais, forçando um projeto de realidade que pode gerar um sentimento de solidão e fazer valer uma iniciativa que se contrapõe à busca por sua independência. Para Sánchez, Martinez e Peñalver (2003) a busca por essa autonomia é um dos primeiros fatores que levam as crianças em um ambiente educacional a tomar consciência de seus próprios sentimentos e experiências, a organizar suas atividades, interesses e curiosidade, e a aumentar seu amadurecimento afetivo e cognitivo. 
De acordo com Brandão (2010) no art. $2^{\circ}$ da LDB a educação é responsabilidade da família e do estado, e é importante que os pais garantam que seus filhos recebam educação. Deve inspirar-se nos princípios da liberdade e proporcionar às crianças as condições necessárias para o gozo de seus direitos e ideais de solidariedade humana com o objetivo de prepará-las e capacitá-las. Na educação escolar, o desenvolvimento integral do aluno é alcançado, considerando que o papel dos pais e das instituições é formar cidadãos que possam trabalhar e viver em sociedade.

\section{CONCLUSÃO}

Este artigo permitiu refletir sobre a importância da família e da escola na educação infantil, destacando a necessidade de ambas atuarem em harmonia para o alcance dos objetivos de aprendizagem da criança.

Nesse sentido, a escola é considerada a instituição responsável pelo processo educativo da criança, mas a família deve assumir um papel ativo nesse processo, estabelecendo uma aliança com a instituição, que na prática se manifesta mutuamente. Por um lado, a família deve supervisionar e participar das atividades escolares e, por outro, a escola deve estar atenta às características da origem da criança e aos valores, expectativas e percepções que surgem do contexto doméstico.

A importância dos aspectos afetivos na relação família / escola, que podem favorecer a fase inicial de adaptação da criança. Destaca-se a importância da família na formação de valores e expectativas e na promoção da autonomia, alicerçada em valores, expectativas e apoio à criança.

Considera-se necessário que a família conheça os objetivos da proposta escolar de acompanhar o desenvolvimento das práticas educativas infantis, e se comprometa com o sucesso na aprendizagem e na formação do indivíduo. Por outro lado, entende-se que a família precisa ser conhecida e valorizada também no contexto escolar, buscando sua integração e envolvimento. 


\section{REFERÊNCIAS}

ARAÚJO, G. B. M. Família e Escola: parceria necessária na educação infantil. 2010. 20 f. Artigo (Especialização em Educação Infantil) - Universidade Católica de Brasília, Brasília, 2010.

ARIÉS. P. História social da criança e da família. Rio de Janeiro: LTC, 2006.

BANDURA, A.; AZZI, R. G.; POLYDORO, S. Teoria Social Cognitiva: conceitos básicos. Porto Alegre: ArtMed, 2008.

BRANDÃO, C. F. LDB Passo a Passo: Lei de Diretrizes e Bases da Educação Nacional, Lei n 9.9394/96 Comentada e Interpretada, Artigo por Artigo. 4. ed. São Paulo: Avercamp, 2010.

BRASIL. Ministério da Educação e do Desporto, Secretaria de Educação Fundamental. Referencial Curricular Nacional para a Educação Infantil. Brasília: MEC/SEF, 1998.

BRITO, M. R. F.; SOUZA, L. F. N. I. Autoeficácia na solução de problemas matemáticos e variáveis relacionadas. Temas em Psicologia, Ribeirão Preto, v. 23, n. I, p. 29-47, 2015.

CASTRO, M. A. S. N. Processos de auto-regulação da aprendizagem: impacto de variáveis académicas e sociais. 2007. 179 f. Dissertação (Mestrado) - Universidade do Minho, Braga, Portugal, 2007.

COSTA, E. R.; BORUCHOVITCH, E. A auto-eficácia e a motivação para aprender. In: AZZI, R. G.; POLYDORO, S. A. J. (Orgs.). Auto-eficácia em diferentes contextos. Campinas, SP: Alínea, 2006.

MASOTTI, D. R. Autoeficácia e autorregulação acadêmica contribuindo para a previsão da evasão escolar. Tear: Revista de Educação Ciência e Tecnologia, Canoas, v. 3, n. 2, 2014.

OLIVEIRA, Z. M. R. Educação infantil: fundamentos e métodos. São Paulo: Cortez, zoII.

PILETTI, N. Sociologia da Educação. São Paulo: Ática, 2004. POLYDORO, S. S. J.; AZZI, R. G. Autorregulação da aprendizagem na perspectiva da teoria sociocognitiva: introduzindo modelos de investigação e intervenção. Psicol. Educ., São Paulo, n. 29, dez. 2009.

SALVADOR, C. C. et al. Psicologia da Educação. Porto Alegre: Artes Médicas Sul, 1999. 
SAMPAIO, R. K. N.; POLYDORO, S. A. J.; ROSÁRIO, P. S. L. F. Autorregulação da aprendizagem e a procrastinação acadêmica em estudantes universitários. Cadernos de Educação, Pelotas, n. 42, p. I19-142, maio/ago. 2012.

SÁNCHEZ, P. A.; MARTINEZ, M. R.; PEÑALVER, I. V. A psicomotricidade na educação infantil: uma prática preventiva e educativa. Porto Alegre: Artemed, 2003. SIMÃO, A. M. V.; FRISON, L. M. B. Autorregulação da aprendizagem: abordagens teóricas e desafios para as práticas em contextos educativos. Cadernos de Educação, Pelotas, n. 45, p. 2-20, maio/ago. 2013.

SOUZA, L. F. N. I. Crenças de auto-eficácia matemática. In: AZZI, R. G.; POLYDORO, S. A. J. (Orgs.). Auto-eficácia em diferentes contextos. Campinas, SP: Alínea, 2006.

SOUZA, M. E. P. Família/Escola: a importância dessa relação no desenvolvimento escolar. 2009. 25 f. Artigo (Programa de Desenvolvimento Educacional) - Universidade Estadual do Norte do Paraná, Santo Antônio da Platina, PR, 2009.

UNESCO. Fontes Para a Educação Infantil Brasília: UNESCO. São Paulo: Cortez; São Paulo: Orsa, 2003. 